\title{
Assessment of the Plantar Pressure, Muscle Strength and Balance in Patients with Type 2 Diabetes Mellitus in Cyprus
}

\author{
Başar Öztürk ${ }^{1}$, Ender Angın², Zehra Güçhan² ${ }^{2}$,asin Yurt' ${ }^{2}$, Mehtap Malkoç² \\ ${ }^{1}$ Department of Physiotherapy and Rehabilitation, Faculty of Health Sciences, Biruni University, Istanbul, \\ Turkey \\ ${ }^{2}$ Department of Physiotherapy and Rehabilitation, Faculty of Health Sciences, Eastern Mediterranean \\ University, Famagusta, Cyprus \\ Email:fztbasarozturk@gmail.com
}

Received 29 March 2016; accepted 14 May 2016; published 17 May 2016

Copyright (C) 2016 by authors and Scientific Research Publishing Inc.

This work is licensed under the Creative Commons Attribution International License (CC BY). http://creativecommons.org/licenses/by/4.0/

(c) (i) Open Access

\begin{abstract}
Aims: Diabetes Mellitus (DM) is a metabolic disorder which affects whole systems of human body. This study aimed to compare the strength of foot muscles, dynamic balance, and peak plantar pressure between diabetic patients before developing polyneuropathy and healthy peers. Methods: 21 people, 11 diabetic patients and 10 age-matched healthy peers, were included in the study. A manual muscle tester (model 01163 Lafayette) was used to assess muscle strength. Pedobarography was the device to determine the distribution of plantar pressure into nine regions of foot. Dynamic balance was also measured by using a mobile platform (Techno-body, PK $200 \mathrm{WL}$, Italy). Results: Diabetic and control groups had similar muscle strength and dynamic balance ( $p>$ $0.05)$. Most of the plantar pressure findings were also similar $(p>0.05)$. There were significant differences in only two regions of foot between two groups $(p<0.05)$. Conclusion: Diabetes Mellitus is not a factor influencing balance and muscle strength before polyneuropathy. However, it is possible to state that it may negatively affect the distribution of plantar pressure so clinians should assess and treat this distribution in the patients with DM.
\end{abstract}

\section{Keywords}

Diabetes, Muscle Strength, Balance, Plantar Pressure

\section{Introduction}

Diabetes Mellitus (DM) is a metabolic disorder which affects functions of various systems in human body. The

How to cite this paper: Öztürk, B., Angın, E., Güçhan, Z., Yurt, Y. and Malkoç, M. (2016) Assessment of the Plantar Pressure, Muscle Strength and Balance in Patients with Type 2 Diabetes Mellitus in Cyprus. Open Journal of Endocrine and Metabolic Diseases, 6, 151-158. http://dx.doi.org/10.4236/ojemd.2016.65020 
prevalence of type 2 diabetes increases rapidly in many countries because of unhealthy life-style changes like inactivity and malnutrition. DM is frequently seen in individuals over 40 years old and causes a common complication which is peripheral polyneuropathy [1] [2]. This is a dysfunction of peripheral and autonomic nerves and leads to loss of sensation, abnormal distribution of plantar pressure of foot, weak foot muscles, and decreased dynamic balance. Proprioceptors of lower extremities get inadequate to transfer correct information and finally static and dynamic postural deviations develop [2] [3]. Postural control may seriously be affected and fall risk threatens life of the patients with DM, so balance assessment is very important for this population [3]. In brief, if the development of polyneuropathy can't be prevented, it may result in foot ulcers, imbalance and even lower extremity amputations.

Almost 40\% - 60\% of all non-traumatic lower extremity amputations depend on diabetes [3]-[5]. It is an important goal to relieve high pressure areas of foot in treatment and an accurate assessment of plantar pressure is crucial to do this [6]. The relationship between plantar pressure and ulceration is a well-known fact but the most potential risky areas of foot are not clear [7]. Patients with type 2 DM have higher risk to develop plantar ulceration than normal population [8] [9]. There are two basic factors leading to ulceration among these patients which are neuropathy and increased plantar pressure values [10] [11].

In addition to abnormal plantar pressure distribution and balance problems, this population may also suffer from muscle strength loss because of aging and neuropathy [12]. While most studies have focused on the patients with polyneuropathy, there is no clear result about the patients with DM only. We aimed to detect if there is any change in plantar pressure distribution, foot muscle strength, and balance before polyneuropathy is developed. Therefore, the purpose of this study was to compare peak plantar pressure, foot muscle strength, and dynamic balance between diabetic patients without polyneuropathy and healthy peers.

\section{Subjects}

This cross-sectional study was conducted in XXXX University. Following the study protocol was approved by the local ethical committee, we contacted to the Cyprus Turkish Diabetes Association in order to invite the people with DM to the study. 21 people, eleven people with DM and ten healthy people, were involved in the study.

People who aged over 40 years and have type 2 DM for at least 2 years were included in the study group. The diabetic patients with peripheral neuropathy (Semmes-Weinstein monofilaments were applied to 10 regions of the foot vertically and no peripheral neuropathy was recorded if patients have no loss of sensation in more than 7 regions) [14] were excluded from the study. Moreover, cases that have no ability to walk independently, have orthopedic, neurological, rheumatic or other metabolic disease, and have plantar ulcer were excluded from the study.

\section{Materials and Methods}

Our research was approved by Biruni University Ethics Commission at 11.02.2016 by LUT 2015-KAEK-43 registration no.

The participants who were found appropriate for the study signed the consent form before the assessments. Demographic information including age and body mass index (BMI) values was recorded. The frequency of falling and duration of DM of the patients were also questioned.

\subsection{Assessment of Muscle Strength}

The isometric muscle strength of the foot invertors, evertors and finger flexor muscles was measured using a Manual Muscle Tester (model 01163 Lafayette). The participants were asked to carry out three maximal isometric contractions for each muscle group, with an interval of $60 \mathrm{~s}$. The mean peak force was recorded by the muscle tester device $(\mathrm{kg})[13]$.

\subsection{Assessment of Peak Plantar Pressure by Pedobarography}

Pedobarography (MediLogic basic, Germany) was used to assess plantar pressure distribution. The time-series of the measured pressure amplitudes of all sensors were grouped into nine anatomical masks (Figure 1). These masks corresponded to the following anatomical areas: the thumb; the second toe; the first metatarsal head; the 


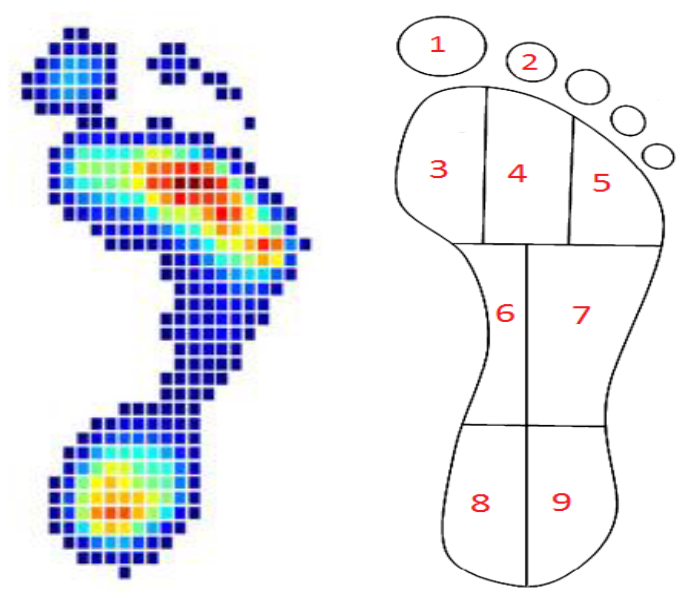

Figure 1. 9 regions of plantar pressure.

second and third metatarsal heads; the forth and fifth metatarsal heads; the navicular bone; the cuboid bone; the medial heel; and the lateral heel. During the experiment of the pressure distribution, the contact area of each mask, and the time of surface contact of each anatomical area were measured.The pressure distribution value $\mathrm{P}^{\mathrm{t}}$ is a quantitative parameter that depends on body mass, a real contact area of foot with the surface with time as:

$$
P^{t} \propto f(m, s, t)
$$

where:

$P^{t}$ - the instantaneous value of plantar pressure,

$m$ - the body mass,

$s$ - the surface contact of each anatomical area $(\mathrm{cm})$,

$t$ - the time of surface contact of each anatomical area.

The pressure value should fit to the full range from zero to the absolute maximum determined by the body mass and the contact area of one sensor [15]. Maximum pressure was defined as the greatest pressure in each anatomical area of foot in a single step, and these values were averaged separately for each mask over 10 steps. The center of pressure was found by a ratio of the sum of products of the element values to the radiusvector, which depended on their coordinates, versus the sum of these values. This center specifies the point of projection onto the pressure vector plane. The configurations may be in the form of spots, graphic primitives or isobaric lines. The anatomic phase of a step is a sequence of the sets of instantaneous values of the plantar pressure during one step limited by the appearance of certain configurations within the frames of anatomic representations [15].

The participants were asked to walk at their natural speed over the plate. At least three measurements were taken. There were three criteria to make the measurements valid: 1) having two complete footprints, 2) having a specific heel strike, 3) having natural footprints which mean that participants should not be observed while trying to correct their feet over the force plate (Figure 2) [16].

\subsection{Assessment of Balance}

A dynamic balance test was conducted to both groups using a mobile platform (Techno-body, PK $200 \mathrm{WL}$, Italy). The participants were asked to stand up over the platform in hands-free position and three measurements were taken to acquire an average score (Figure 3 \& Figure 4) [17].

All tests were done by the same author who was blinded about the group of participants. All assessments were completed barefoot. A few resting minutes were given to the participants between the tests.

\section{Statistical Analysis}

Data was analyzed using statistical package for social sciences (SPSS) 20.0 for windows. Difference at $\mathrm{p}<0.05$ level was considered to be statistically significant. Mann-Whitney U test was used after normality of data was not observed, to determine differences between groups. Median or Mean \pm Standart Deviation $(\mathrm{X} \pm \mathrm{SD})$ were used 


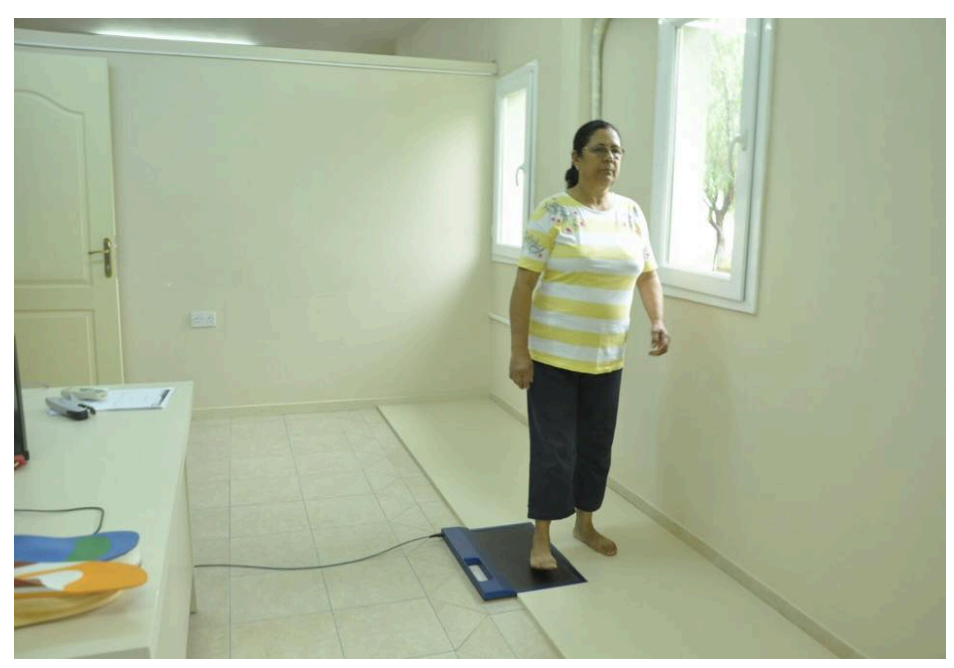

Figure 2. Pedobarography.

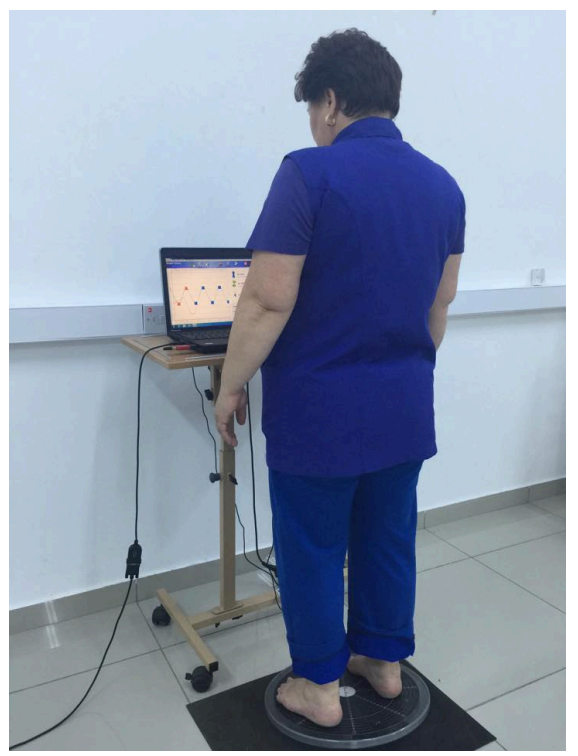

Figure 3. Techno-body.

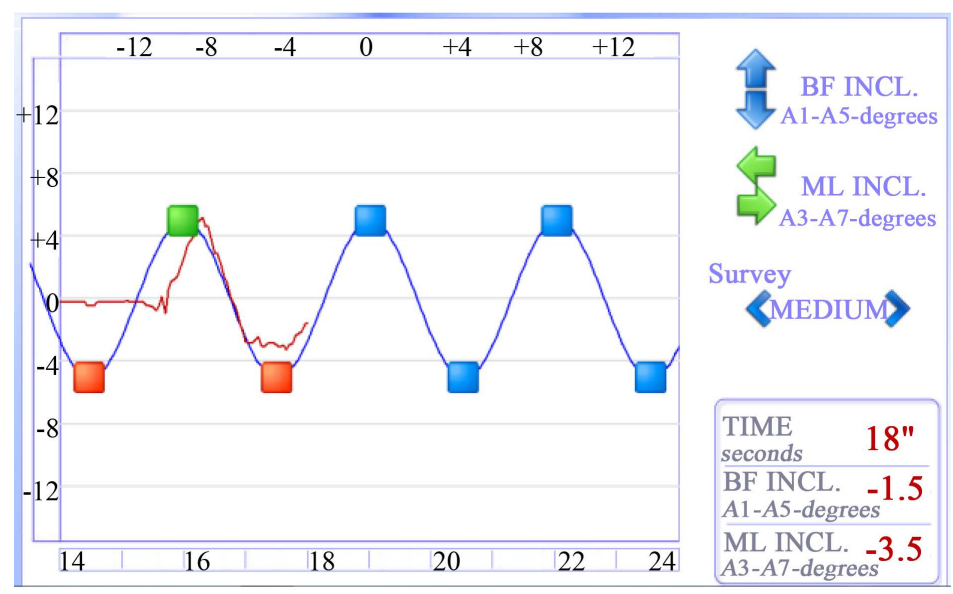

Figure 4. Techno-body data. 
to indicate results clearly.

\section{Results}

11 type 2 diabetic individuals (48.54 \pm 7.48 years; 7 female, 4 male) and 10 age-matched control subjects (45.8 \pm 4.6 year; 5 female, 5 male) participated. Their BMI were $30.74 \pm 4.97$ and $25.37 \pm 3.07 \mathrm{~kg} / \mathrm{m}^{2}$. Mean duration of DM of the patients was $5.18 \pm 2.71$ years (Table 1). There was no falling story of the participants.

Table 2 shows the comparison of muscle strengths between two groups and indicates no statistical difference between them. The findings related to balance are also seen in Table 3 and no statistical difference is observed. Statistical difference was found in the pressure of two plantar regions between the groups (Table 4).

\section{Discussion}

A healthy foot assessment is essential in patients with DM to determine biomechanical sways and incorrect distribution of plantar pressure [18]. Thus, ulceration and even amputation in lower limb may be prevented. This study aimed to specify the effects of the DM disease on plantar pressure, the strength of foot muscles and balance. We indicated that only plantar pressure was affected by the presence of DM without polyneuropathy.

There are two factors of developing ulceration among the patients with DM which are neuropathy and high plantar pressure values. These may cause loss of sensation, loss of muscle strength, and balance problem [19]. In our study, an increase in the pressure of the forefoot part of plantar region was determined. Similarly, Robinson et al. [20] indicated that not only the patients with DM but also people who have risk of developing DM may have changes in foot plantar pressure. In the same study by Robinson et al., an increase in the pressure of forefoot was shown. According to the study of Rahman et al. [7] there was an increase in pressure of forefoot and a decrease in pressure of rear foot.

Table 1. Demographic features of subjects.

\begin{tabular}{ccc}
\hline & Diabetic group $(\mathbf{X} \pm \mathbf{S D})$ & Healthy group $(\mathbf{X} \pm \mathbf{S D})$ \\
\hline Age (years) & $48.54 \pm 7.48$ & $46.44 \pm 4.61$ \\
Diabetes duration (years) & $5.18 \pm 2.71$ & - \\
Body mass index $\left(\mathbf{k g} / \mathbf{m}^{2}\right)$ & $30.74 \pm 4.97$ & $25.37 \pm 3.07$ \\
\hline
\end{tabular}

Table 2. Muscle strentgh assesment of the groups.

\begin{tabular}{|c|c|c|c|c|c|}
\hline & $\begin{array}{l}\text { Diabetic group } \\
\quad(X \pm S D)\end{array}$ & Median & $\begin{array}{l}\text { Healthy group } \\
\quad(X \pm S D)\end{array}$ & Median & $\mathbf{p}$ \\
\hline $\begin{array}{l}\text { Inversion muscle strength } \\
\text { of right foot (kg-f) }\end{array}$ & $5.83 \pm 3.76$ & 5.03 & $5.53 \pm 1.68$ & 5.65 & 0.45 \\
\hline $\begin{array}{l}\text { Inversion muscle strength } \\
\text { of left foot (kg-f) }\end{array}$ & $6.16 \pm 4.05$ & 5.13 & $5.84 \pm 1.79$ & 6.10 & 0.48 \\
\hline $\begin{array}{l}\text { Eversion muscle strength } \\
\text { of right foot (kg-f) }\end{array}$ & $5.38 \pm 3.21$ & 4.77 & $5.41 \pm 1.72$ & 5.38 & 0.29 \\
\hline $\begin{array}{l}\text { Eversion muscle strength of } \\
\text { left foot (kg-f) }\end{array}$ & $5.14 \pm 3.90$ & 4.37 & $5.15 \pm 1.42$ & 5.40 & 0.16 \\
\hline $\begin{array}{l}\text { Instrinsic muscle strength of } \\
\text { right foot (kg-f) }\end{array}$ & $6.32 \pm 4.94$ & 4.77 & $4.63 \pm 1.59$ & 4.40 & 0.77 \\
\hline $\begin{array}{l}\text { Instrinsic muscle strength } \\
\text { of left foot (kg-f) }\end{array}$ & $6.25 \pm 5.65$ & 4.00 & $4.32 \pm 1.39$ & 4.67 & 0.91 \\
\hline
\end{tabular}

Table 3. Balance assesment of the groups.

\begin{tabular}{ccccc}
\hline & $\begin{array}{c}\text { Diabetic group } \\
(\mathbf{X} \pm \text { SD) }\end{array}$ & Median & $\begin{array}{c}\text { Healthy group } \\
\text { (X } \pm \text { SD) }\end{array}$ & Median \\
\hline Balance scores (points) & $4.36 \pm 1.43$ & 4.00 & $4.20 \pm 1.39$ & 4.00 \\
\hline
\end{tabular}


Table 4. Plantar Pressure assessments of groups.

\begin{tabular}{|c|c|c|c|c|c|}
\hline & $\begin{array}{l}\text { Diabetic group } \\
\quad(X \pm S D)\end{array}$ & Median & $\begin{array}{l}\text { Healthy group } \\
\text { (X } \pm \text { SD) }\end{array}$ & Median & $\mathbf{p}$ \\
\hline Plantar pressure 1st region of right foot $\left(\mathrm{N} / \mathrm{cm}^{2}\right)$ & $36.81 \pm 18.56$ & 43.20 & $35.78 \pm 21.36$ & 39.40 & 0.45 \\
\hline Plantar pressure 2nd region of right foot $\left(\mathrm{N} / \mathrm{cm}^{2}\right)$ & $17.58 \pm 7.86$ & 16.30 & $12.51 \pm 5.32$ & 15.30 & 0.18 \\
\hline Plantar pressure 3rd region of right foot $\left(\mathrm{N} / \mathrm{cm}^{2}\right)$ & $25.22 \pm 12.89$ & 22.55 & $30.21 \pm 15.46$ & 26.40 & 0.43 \\
\hline Plantar pressure 4th region of right foot $\left(\mathrm{N} / \mathrm{cm}^{2}\right)$ & $45.14 \pm 16.86$ & 47.20 & $38.44 \pm 4.43$ & 40.20 & 0.35 \\
\hline Plantar pressure 5 th region of right foot $\left(\mathrm{N} / \mathrm{cm}^{2}\right)$ & $18.79 \pm 6.74$ & 16.20 & $20.80 \pm 18.21$ & 16.30 & 0.77 \\
\hline Plantar pressure 6th region of right foot $\left(\mathrm{N} / \mathrm{cm}^{2}\right)$ & $6.39 \pm 4.89$ & 6.00 & $5.21 \pm 4.61$ & 4.50 & 0.83 \\
\hline Plantar pressure 7 th region of right foot $\left(\mathrm{N} / \mathrm{cm}^{2}\right)$ & $12.54 \pm 3.53$ & 12.30 & $10.98 \pm 7.87$ & 10.50 & 0.30 \\
\hline Plantar pressure 8th region of right foot $\left(\mathrm{N} / \mathrm{cm}^{2}\right)$ & $19.54 \pm 7.51$ & 16.30 & $26.88 \pm 10.46$ & 30.40 & 0.13 \\
\hline Plantar pressure 9th region of right foot $\left(\mathrm{N} / \mathrm{cm}^{2}\right)$ & $20.30 \pm 7.24$ & 17.30 & $24.05 \pm 9.08$ & 24.30 & 0.24 \\
\hline Plantar pressure 1th region of left foot $\left(\mathrm{N} / \mathrm{cm}^{2}\right)$ & $41.44 \pm 22.44$ & 50.85 & $39.77 \pm 21.58$ & 38.10 & 0.88 \\
\hline Plantar pressure 2th region of left foot $\left(\mathrm{N} / \mathrm{cm}^{2}\right)$ & $13.07 \pm 11.38$ & 11.25 & $13.96 \pm 6.74$ & 13.30 & 0.34 \\
\hline Plantar pressure 3th region of left foot $\left(\mathrm{N} / \mathrm{cm}^{2}\right)$ & $25.40 \pm 13.92$ & 21.30 & $20.27 \pm 11.35$ & 15.10 & 0.02 \\
\hline Plantar pressure 4 th region of left foot $\left(\mathrm{N} / \mathrm{cm}^{2}\right)$ & $47.94 \pm 12.88$ & 45.30 & $29.33 \pm 13.77$ & 24.30 & 0.003 \\
\hline Plantar pressure 5th region of left foot $\left(\mathrm{N} / \mathrm{cm}^{2}\right)$ & $18.26 \pm 4.83$ & 18.30 & $18.92 \pm 8.46$ & 18.60 & 1.00 \\
\hline Plantar pressure 6th region of left foot $\left(\mathrm{N} / \mathrm{cm}^{2}\right)$ & $6.77 \pm 5.74$ & 5.75 & $5.15 \pm 4.44$ & 6.80 & 0.39 \\
\hline Plantar pressure 7th region of left foot $\left(\mathrm{N} / \mathrm{cm}^{2}\right)$ & $10.86 \pm 6.77$ & 12.30 & $7.06 \pm 5.25$ & 8.50 & 0.12 \\
\hline Plantar pressure 8th region of left foot $\left(\mathrm{N} / \mathrm{cm}^{2}\right)$ & $18.94 \pm 3.69$ & 18.30 & $20.43 \pm 6.00$ & 19.30 & 0.91 \\
\hline Plantar pressure 9th region of left foot $\left(\mathrm{N} / \mathrm{cm}^{2}\right)$ & $17.28 \pm 3.04$ & 17.45 & $20.31 \pm 6.34$ & 18.80 & 0.52 \\
\hline
\end{tabular}

Limitations of ankle range of motion are common among people with DM. Limitation of dorsal flexion causes shorter heel strike duration so increased loading to forefoot and higher pressure in forefoot are expected [21] [22]. Therefore, the current literature supports an increase in forefoot among people with DM. In addition, structural impairments of foot and high obesity prevalence of people with DM also lead to increased plantar pressure [21] [22]. Turner et al. [23] also reported that plantar pressure may increase due to the biomechanical dysfunction of foot, particularly at 1 . Metatarsophalangeal joint region and this may cause ulceration in foot. Briefly, the results of this paper about plantar pressure were supported by the literature.

Decreased protective sensation among the patients with DM explains the cause of intrinsic muscle dysfunction and anhidrosis of foot. Moreover, foot deformities observed in DM populationmay also be related to imbalance of foot muscle strength [24] [25]. Ijzerman et al. [26] determined decreased maximal contraction strength of plantar and dorsal flexor muscles among people with type $2 \mathrm{DM}$. Balducci et al. [27] claimed that weak ankle-foot muscles are related to denervation of nerves in patients with DM. Furthermore, Cavanach et al. [24] indicated that these patients have weak intrinsic foot muscles. Similarly, Ijzerman et al. [26] claimed that the strength of calf muscles decreases by $30 \%-50 \%$. This is also another factor which causes an increase in plantar pressure. Therefore, both the strength of intrinsic muscles and the distribution of plantar pressure were assessed in this study. However, DM was not found to be a factor which influenced the muscle strength in our study. This can be explained that muscle strength may decrease following polyneuropathy in people with DM.

Various papers indicated that balance is negatively affected in diabetic patients with neuropathy [19] [22]. According to Haghighi, the sensations of proprioception and kinesthesia are destroyed in patients with type 2 DM, even without neuropathy [28]. However, no author investigated the effects of DM on the balance of these patients. Thus, this paper is the first that investigated whether balance is affected in the patients with DM when it was compared with the healthy peers. As a result, no significant difference was determined between the balance findings of the groups. This may be explained like that impairment of proprioception may affect the balance when the patients with DM develop neuropathy.

Oliveira et al. [29] investigated the relationship between the plantar pressure distribution and balance of the 
people with DM. They used force platforms while assessing both plantar pressure and balance of the participants. They also found the highest plantar pressure under the forefoot. However, no relationship was found between postural oscillations and the forefoot pressure, while there was a relationship between higher pressure of rear foot and postural oscillations. This may explain the reason of our finding as the patients in this study had similar plantar pressure in the rear foot to the healthy peers.

As a result, DM causes significant increase in the plantar pressure of the forefoot even without neuropathy, whereas the strength of foot muscles and dynamic balance are not affected. Calculated statistical power for our most prominent result was $90 \%$ and it makes the result clinically significant. Nevertheless, larger sample size is required to generalise these findings. In conclusion, we consider that this paper will guide the health professionals assess the change in plantar pressure of the patients with DM, even without any complication.

\section{References}

[1] Melai, T., Schaper, N.C., Ijzerman, T.H., de Lange, T.L., Willems, P.J., Meijer, K., Lieverse, A.G. and Savelberg, H.H. (2013) Increased Forefoot Loading Is Associated with an Increased Plantar Flexion Moment. Human Movement Science, 32, 785-793. http://dx.doi.org/10.1016/j.humov.2013.05.001

[2] Allet, L., Armand, S., Aminian, K., Pataky, Z., Golay, A., de Bie, R.A. and de Bruin, E.D. (2010) An Exercise Intervention to Improve Diabetic Patients' Gait in a Real-Life Environment. Gait \& Posture, 32, 185-190. http://dx.doi.org/10.1016/j.gaitpost.2010.04.013

[3] Ghanavati, T., Shaterzadeh Yazdi, M.J., Goharpey, S. and Arastoo, A.A. (2012) Functional Balance in Elderly with Diabetic Neuropathy. Diabetes Research and Clinical Practice, 96, 24-28. http://dx.doi.org/10.1016/j.diabres.2011.10.041

[4] Kluding, P.M., Pasnoor, M., Singh, R., Jernigan, S., Farmer, K., Rucker, J., Sharma, N.K. and Wright, D.E. (2012) The Effect of Exercise on Neuropathic Symptoms, Nerve Function, and Cutaneous Innervation in People with Diabetic Peripheral Neuropathy. Journal of Diabetes and Its Complications, 26, 424-429. http://dx.doi.org/10.1016/j.jdiacomp.2012.05.007

[5] Giacomozzi, C., Caselli, A., Macellari, V., Giurato, L., Lardieri, L. and Uccioli, L. (2002) Walking Strategy in Diabetic Patients with Peripheral Neuropathy. Diabetes Care, 25, 1451-1457. http://dx.doi.org/10.2337/diacare.25.8.1451

[6] Drerup, B., Szczepaniak, A. and Wetz, H.H. (2008) Plantar Pressure Reduction in Step-to Gait: A Biomechanical Investigation and Clinical Feasibility Study. Clinical Biomechanics (Bristol, Avon), 23, 1073-1079. http://dx.doi.org/10.1016/j.clinbiomech.2008.04.014

[7] Sacco, I.C., Hamamoto, A.N., Tonicelli, L.M., Watari, R., Ortega, N.R. and Sartor, C.D. (2014) Abnormalities of Plantar Pressure Distribution in Early, Intermediate, and Late Stages of Diabetic Neuropathy. Gait \& Posture, 40, 570574. http://dx.doi.org/10.1016/j.gaitpost.2014.06.018

[8] Rahman, M.A., Aziz, Z., Rajendra Acharya, U., Ha, T.P., Kannathal, N., Ng, E.Y.K., Fang, S.C., et al. (2006) Analysis of Plantar Pressure in Diabetic Type 2 Subjects with and without Neuropathy. ITBM-RBM, 27, 46-55. http://dx.doi.org/10.1016/j.rbmret.2006.03.001

[9] Colberg, S.R. (2006) The Impact of Exercise on Insulin Action in Type 2 Diabetes Mellitus: Relationship to Prevention and Control. Insulin, 1, 85-98. http://dx.doi.org/10.1016/S1557-0843(06)80018-7

[10] Savelberg, H.H., Schaper, N.C., Willems, P.J., de Lange, T.L. and ve Meijer, K. (2009) Redistribution of Joint Moments Is Associated with Changed Plantar Pressure in Diabetic Polyneuropathy. BMC Musculoskeletal Disorders, 2, 10-16.

[11] Nakanishi, S., Takezawa, G., Taooka, Y., Kikkawa, K., Matsumoto, N. and Hidaka, T. (2014) Gait Speed May Predict Development of Type 2 Diabetes: A Pilot Study among Elderly Japanese. Journal of Diabetes Mellitus, 4, 38-43. http://dx.doi.org/10.4236/jdm.2014.41007

[12] Abizanda, P., Navarro, J.L., García-Tomás, M.I., López-Jiménez, E., Martínez-Sánchez, E. and Paterna, G. (2012) Validity and Usefulness of Hand-Held Dynamometry for Measuring Muscle Strength in Community-Dwelling Older Persons. Archives of Gerontology and Geriatrics, 54, 21-27. http://dx.doi.org/10.1016/j.archger.2011.02.006

[13] Santos, K.M.S., Cerqueira Neto, M.L.D., Carvalho, V.O., Santana Filho, V.J.D., Junior, S., Araújo Filho, A.A., et al. (2014) Evaluation of Peripheral Muscle Strength of Patients Undergoing Elective Cardiac Surgery: A Longitudinal Study. Revista Brasileira de Cirurgia Cardiovascular, 29, 355-359. http://dx.doi.org/10.5935/1678-9741.20140043

[14] Acharya, R., Tan, P.H., Subramaniam, T., Tamura, T., Chua, K.C., Goh, S.C.E., et al. (2008) Automated Identification of Diabetic Type 2 Subjects with and without Neuropathy Using Wavelet Transform on Pedobarograph. Journal of Medical Systems, 32, 21-29. http://dx.doi.org/10.1007/s10916-007-9103-y

[15] Pauk, J., Daunoraviciene, K., Ihnatouski, M., Griskevicius, J. and Raso, J.V. (2010) Analysis of the Plantar Pressure Distribution in Children with Foot Deformities. Acta of Bioengineering and Biomechanics, 12, 29-34. 
[16] Gurney, J.K., Kersting, U.G. and Rosenbaum, D. (2008) Between-Day Reliability of Repeated Plantar Pressure Distribution Measurements in a Normal Population. Gait \& Posture, 27, 706-709. http://dx.doi.org/10.1016/j.gaitpost.2007.07.002

[17] Camliguney, A.R., Atiglan, N., Yilmaz, O. and Uzun, S.S. (2012) The Effects of Intensive Ski Training on Postural Balance Athletes. International Journal of Humanities and Social Science, 2, 71-79.

[18] Skopljak, A., Sukalo, A., Batic-Mujanovic, O., Becirevic, M., Tiric-Campara, M. and Zunic, L. (2014) Assessment of Diabetic Polyneuropathy and Plantar Pressure in Patients with Diabetes Mellitus in Prevention of Diabetic Foot. Medical Archives, 68, 389-393. http://dx.doi.org/10.5455/medarh.2014.68.389-393

[19] Turcot, K., Allet, L., Golay, A., Hoffmeyer, P. and Armand, S. (2009) Investigation of Standing Balance in Diabetic Patients with and without Peripheral Neuropathy Using Accelerometers. Clinical Biomechanics, 24, 716-721. http://dx.doi.org/10.1016/j.clinbiomech.2009.07.003

[20] Robinson, C.C., Balbinot, L.F., Silva, M.F., Achaval, M. and Zaro, M.A. (2013) Plantar Pressure Distribution Patterns of Individuals with Prediabetes in Comparison with Healthy Individuals and Individuals with Diabetes. Journal of Diabetes Science and Technology, 7, 1113-1121. http://dx.doi.org/10.1177/193229681300700503

[21] Shen, J., Liu, F., Zeng, H., Wang, J., Zhao, J.G., Zhao, J., et al. (2012) Vibrating Perception Threshold and Body Mass Index Are Associated with Abnormal Foot Plantar Pressure in Type 2 Diabetes Outpatients. Diabetes Technology \& Therapeutics, 14, 1053-1059. http://dx.doi.org/10.1089/dia.2012.0146

[22] Van Deursen, R. (2004) Mechanical Loading and Off-Loading of the Plantar Surface of the Diabetic Foot. Clinical Infectious Diseases, 39, S87-S91. http://dx.doi.org/10.1086/383268

[23] Turner, D.E., Helliwell, P.S., Burton, A.K. and Woodburn, J. (2007) The Relationship between Passive Range of Motion and Range of Motion during Gait and Plantar Pressure Measurements. Diabetic Medicine, 24, 1240-1246. http://dx.doi.org/10.1111/j.1464-5491.2007.02233.x

[24] Cavanagh, P.R., Ulbrecht, J.S. and Caputo, G.M. (2000) New Developments in the Biomechanics of the Diabetic Foot. Diabetes/Metabolism Research and Reviews, 16, S6-S10. http://dx.doi.org/10.1002/1520-7560(200009/10)16:1+<::AID-DMRR130>3.0.CO;2-Z

[25] Shenoy, A.M. (2012) Guidelines in Practice: Treatment of Painful Diabetic Neuropathy. CONTINUUM: Lifelong Learning in Neurology, Peripheral Neuropathy, 18, 192-198.

[26] IJzerman, T.H., Schaper, N.C., Melai, T., Meijer, K., Willems, P.J. and Savelberg, H.H. (2012) Lower Extremity Muscle Strength Is Reduced in People with Type 2 Diabetes, with and without Polyneuropathy, and Is Associated with Impaired Mobility and Reduced Quality of Life. Diabetes Research and Clinical Practice, 95, 345-351. http://dx.doi.org/10.1016/j.diabres.2011.10.026

[27] Balducci, S., Sacchetti, M., Orlando, G., Salvi, L., Pugliese, L., Salerno, G., et al. (2014) Correlates of Muscle Strength in Diabetes: The Study on the Assessment of Determinants of Muscle and Bone Strength Abnormalities in Diabetes (SAMBA). Nutrition, Metabolism and Cardiovascular Diseases, 24, 18-26. http://dx.doi.org/10.1016/j.numecd.2013.04.010

[28] Haghighi, F.M. (2014) Evaluation of Knee Proprioception and Kinesthesia in Patients with Type 2 Diabetes Mellitus. Nigerian Journal of Medical Rehabilitation, 17, 1-12.

[29] Anjos, D.M., Gomes, L.P., Sampaio, L.M., Correa, J.C. and Oliveira, C.S. (2010) Assessment of Plantar Pressure and Balance in Patients with Diabetes. Archives of Medical Science, 6, 43-48. http://dx.doi.org/10.5114/aoms.2010.13506 